\title{
Drosophila Mushroom Bodies Are Dispensable for Visual, Tactile, and M otor Learning
}

Reinhard Wolf, Tobias Wittig, Li Liu, Gerold Wustmann, Dirk Eyding, ${ }^{1}$ and Martin Heisenberg ${ }^{2}$

Lehrstuhl für Genetik

Biozentrum

D-97074 Würzburg, Germany

\begin{abstract}
A total of 18 associative learning/ memory tests have been applied to Drosophila mela nogaster flies lacking mushroom bodies. Only in paradigms involving chemosensory cues as conditioned stimuli have flies been found to be compromised by a block in the mushroom body pathway. Among the learning tasks not requiring these structures are a case of motor learning (yaw torque/ heat), a test of the fly's spatial orientation in total darkness, conditioned courtship suppression by mated females, and nine different examples of visual learning. The latter used the reinforcers of heat, visual oscillations, mechanical shaking, or sucrose, and as conditioned stimuli, color, intensity contrast, as well as stationary and moving visual patterns. No forms of consolidated memory have been tested in mushroom body-less flies. With respect to short-term memory the mushroom bodies of Drosophila are specially required for chemosensory learning tasks, but not for associative learning and memory in general.
\end{abstract}

\section{Introduction}

Possible roles of the insect mushroom bodies (corpora pedunculata) in behavior have been de-

${ }^{1}$ Present address: Institut für Physiologie, Abt. Neurophysiologie, Ruhr-Universität Bochum, D-44780 Bochum, Germany.

${ }^{2}$ Corresponding author. bated for nearly 150 years (Dujardin 1850). It took more than a century before some of the hypotheses could be tested experimentally and even then, the means of intervention proved unsatisfactory. Lesions and electrical stimulation in the mushroom bodies (MBs) caused a large variety of behavioral symptoms that were difficult to reconcile with a common function (for review, see Erber et al. 1987). Among the behavioral properties affected by lesions were cocoon spinning in Cecropia larvae (van der Kloot and Williams 1954), the organization of behavioral sequences in bees and locusts (Howse 1974), odor thresholds and optomotor latencies in the cockroach (Drescher 1960), as well as the suppression of locomotor activity in crickets and grasshoppers (Huber 1960). Fortunately, one behavioral impairment has now been consistently found with different lesioning techniques and in different insect species: olfactory learning and memory.

First hints indicating that the MBs are required for the retention of odors came from extensive bilateral lesions in bees (Voskresenskaja 1957) and ants (Vowles 1964). Later, Masuhr (1976) applied more confined lesions in the calyces or $\alpha$-lobes of the honeybee with similar results. Subsequently, he developed a special probe for locally cooling small areas of the bee brain. With this elegant technique he was able to interfere with short-term memory in the antennal lobe, calyces, or $\alpha$-lobe (Erber et al. 1980). A decade later, two Drosophila mutants with severe structural defects in the MBs, but entirely different etiologies of the mutant defects, were shown to be impaired in olfactory memory (Heisenberg et al. 1985). A further decade later, it became possible to ablate the MBs in wildtype Drosophila by applying a cytostatic drug, hy-

LEARN IN G \& MEM ORY 5:166-178 @ 1998 by Cold Spring Harbor Laboratory Press ISSN 1072-0502/98 \$5.00

$$
\begin{array}{llllllllllllllll}
L & E & A & R & N & I & N & G & \underset{166}{\mathbf{X}} & M & E & M & O & R & Y
\end{array}
$$


droxyurea (HU), to the first larval instar (Prokop and Technau 1994). The result was the same-a severe defect in olfactory memory (de Belle and Heisenberg 1994). Recently, Connolly et al. (1996) went a step farther and confined the block to the Kenyon cells by specifically expressing a constitutively activated $G \alpha_{s}$ protein subunit in these cells. Again, odor retention was specifically impaired. If the expression of the mutated transgene leaves the circuitry of the MB pathway intact, the experiment shows that blocking modulation of the Kenyon cell output synapses is sufficient to impair olfactory memory.

The cumulative evidence from hymenopterans and flies leaves little doubt that MBs are involved in olfactory memory. This finding calls to mind the proposal of Hanström (1928), suggesting that the MBs may be general association organs. The MBs do receive many types of sensory input (for review, see Erber et al. 1987; Schürmann 1987), and in Drosophila the MBs have been show $n$ recently to be structurally affected by visual experience (Barth and Heisenberg 1997). However, outside the realm of chemoreception little evidence supports Hanström's view. Flies of the mushroom bodies deranged (mbd) mutant stock with severely defective MBs have been show $n$ to remember colors (Heisenberg et al. 1985; Heisenberg 1989). Moreover, mutant mbd as well as mushroom body miniature ${ }^{1}\left(\mathrm{mbm}^{1}\right)$ flies are able to reorganize their visuomotor interface in response to inverted coupling in the flight simulator (preliminary data cited in Heisenberg 1989).

Here we reinvestigate the question whether the MBs might be involved in visual and other kinds of associative learning and memory besides odor preference conditioning. We take advantage of the HU ablation technique (Prokop and Technau 1994) for the generation of MB-less flies (HU-flies). The HU technique seems particularly suited for studying the role of the MBs in visual behavior because the optic anlagen do not start postembryonic development until after $\mathrm{HU}$ treatment (Ito and Hotta 1991). The volume of the adult optic lobes is not affected in HU flies (deBelle and Heisenberg 1994). In the time window of the treatment, in each brain hemisphere only five neuroblasts proliferate. Four of them, the MB neuroblasts, give birth to the postembryonic Kenyon cells, and a fifth one generates neurons of the antennal lobe (Ito and Hotta 1991; Prokop and Technau 1994). In the adult animal, HU treatment leads to the virtually complete absence of MBs and, in addition, to a
$30 \%$ reduction of the volume of the antennal lobe (de Belle and Heisenberg 1994).

In this study we test MB-less flies in six learning paradigms, four of which involve visual orientation. Five are operant and one is a classic form of conditioning. In four paradigms, the animals are tethered in flight; in tw o paradigms, freely walking flies are tested. Different kinds of reinforcements and various conditioned stimuli are used. In all these situations MB-less flies perform as well as normal ones. The involvement of the MBs in learning and memory seems to be confined to olfaction and possibly taste.

\section{Materials and Methods}

\section{FLIES}

All flies tested, with or without MBs, were between 2 and 6 days old and were maintained at $25^{\circ} \mathrm{C}$ on standard corn meal/molasses medium (for recipe, see Guo et al. 1996) in a 16-hr light/ $8 \mathrm{hr}$ dark cycle at $60 \%$ humidity. For all flight experiments only female flies were used. Wild-type flies were from the strain "Berlin" (WT Berlin). For the experiment in Figure 3 (below), the mutant $\mathrm{mbm}^{1}$ (Heisenberg et al. 1985) was used, which is kept as a homozygous stock in the genetic background of WT Berlin.

For ablation of MB neuroblasts (Prokop and Technau 1994) 150 first instar larvae (maximum age, $1 \mathrm{hr}$ ) were collected and mixed with $1 \mathrm{ml}$ of a suspension containing precooked baker's yeast and $60 \mathrm{mg}$ of $\mathrm{HU}$. After $4 \mathrm{hr}$ of exposure to $\mathrm{HU}$, larvae were carefully rinsed with water and transferred to fresh food vials. To avoid any confusion from handling artifacts, HU flies and controls were bred strictly in parallel, with the only difference that HU was omitted for the controls. All HU flies that successfully passed the behavioral tests were subjected to postmortem histology. Rare individuals with detectable remnants of MBs ( 2\%-4\%) were not included in the behavioral data.

\section{APPARATUS}

\section{FLIGHT SIMULATOR}

For the flight simulator (Heisenberg and Wolf 1988), single flies were glued by their head and thorax to a small hook of copper wire $(0.05 \mathrm{~mm}$ diam.); the hook was attached to a torque meter. The torque meter was positioned in the center of a circular arena that could be rotated by a fast elec- 
Wolf et al.

tric motor. The angular velocity of the arena was made negatively proportional to the voltage output of the torque meter (flight simulator). Thus, instead of rotating the fly in a stationary surround, the fly's yaw torque rotated the panorama around the stationary fly. As reinforcement the fly was heated by an infrared beam (Wolf and Heisenberg 1991) that could be intercepted by an electric shutter (Fig. 1) controlled, in turn, by the fixed schedule of a computer program (classic conditioning, Fig. 5, below), or by the fly's flight direction with respect to the arena (operant conditioning, Figs. 2-4). The arena carried two upright and two inverted T-shaped landmarks (width, 39 ; height, $36^{\circ}$; thickness of horizontal and vertical T-bars, $12^{\circ}$; as seen from the position of the fly in the center of the arena). For the experiment of Figure 4 , instead of heat the arena was oscillated (peakto-peak amplitude, $A_{p p}= \pm 7.5^{\circ}$; frequency, $f=5$ $\mathrm{Hz}$ ) as a negative reinforcement. The exafferent oscillations were generated by a computer program and superimposed on the reafferent movement of the arena at the appropriate flight directions. Yaw torque and flight direction were recorded continuously and stored in the computer memory (sampling frequency, $20 \mathrm{~Hz}$ ) for further evaluation of data. Experimental procedures are further described in the text and figure legends.

\section{HEATING CHAMBER}

The heating chamber has been described by Wustmann et al. (1996). The upper and lower surfaces of the laterally transparent rectangular chamber $\left(40 \times 4 \times 2.5 \mathrm{~mm}^{3}\right)$ consisted of Peltier elements. A control circuit and a thermosensor in the chamber kept the Peltier elements at a permissive "cold" $\left(25^{\circ} \mathrm{C} \pm 2^{\circ} \mathrm{C}\right)$ or restrictive "hot" $\left(37^{\circ} \mathrm{C} \pm 2^{\circ} \mathrm{C}\right)$ temperature. The chamber was virtually subdivided perpendicular to its long axis into two halves by a directionally selective infrared light gate (Fig. 7e, below) invisible to the fly (for spectral sensitivity of Drosophila, see Heisenberg and Wolf 1984). The chamber was illuminated by four small lamps close to the corners of the alley (Fig. $7 a, b)$ that were switched off in the experiment of Figure $7, c$ and $d$. The supervising computer continuously monitored the time and directions of transitions at the light gate. During training, in addition, it turned heat on when the fly entered one side and turned it off when the fly moved to the other side. A rack with 15 chambers was used for the experiments. Therefore, it was possible to test 15 flies at the same time (for further details, see also Wustmann and Heisenberg 1997). The experiments consisted of three phases: a preference test block of 30-sec duration, four training blocks ( 30 sec each), and two memory tests (30 sec each). After training, the memory tests did not start until the fly crossed the light gate from the previously hot to the cold side. Therefore, inactive flies were excluded and all flies experienced the low temperature on the previously hot side before the onset of the memory test period. Between consecutive trials the sides for the permissive and restrictive conditions were switched.

\section{ANALYSIS OF DATA}

The performance of individual flies was calcu-
Figure 1: Drosophila flight simulator with heat reinforcement. (a) Yaw torque of a single stationarily flying fly is continuously recorded. Corresponding angular movements are calculated from yaw torque and are visually fed back to the fly as angular velocity and pattern position of the panorama. During regular training (Figs. 2,3,5) heat reinforcement is switched on or off by an electric shutter, which in operant training is controlled by the fly's flight direction with respect to the T-shaped landmarks. In classic training (Fig. 5) the shutter is controlled by the fixed schedule of a computer program. For more details, see text and Materials and Methods. (b) Block diagram of the learning paradigm in the flight simulator. a

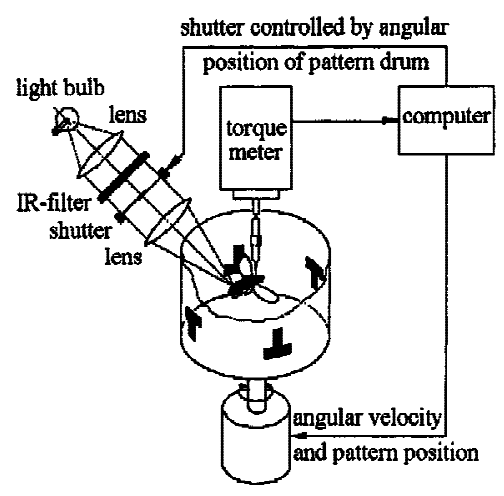

b

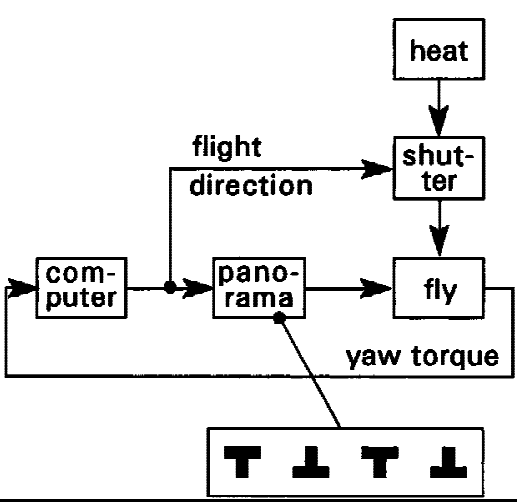

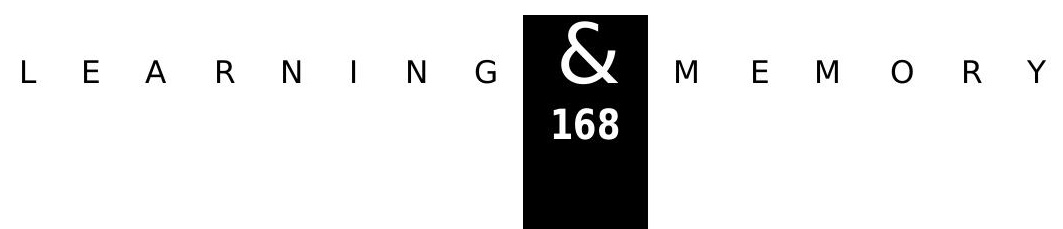


lated as performance index: $\mathrm{PI}=\left(\mathrm{t}_{\mathrm{a}}-\mathrm{t}_{\mathrm{b}}\right) /\left(\mathrm{t}_{\mathrm{a}}+\mathrm{t}_{\mathrm{b}}\right)$. During training, $t_{b}$ indicates the time the fly was exposed to the reinforcer and $t_{a}$ the time without reinforcement. Because during test the reinforcement was permanently switched off, $t_{a}$ and $t_{b}$ refer to the times in which the experimental situations corresponded to the respective permissive or restrictive training situations. To test the significance of the differences between memory scores (PIs of memory tests) in MB-less and control flies the twosided $\mathrm{P}$ value [alternate t-test for assumed Gaussian populations with different standard deviations (Welch test)] was calculated (Sachs 1992). All error bars in figures are S.E.M.

\section{Results}

\section{OPERANT VISUAL LEARNING IN THE FLIGHT SIMULATOR}

HU flies showed no obvious impairments. In the culture vials, they were actively walking around and could be observed grooming, jumping, and courting. For the flight experiments single females of the $\mathrm{HU}$ and control groups w ere cooled to $\sim 6^{\circ} \mathrm{C}-8^{\circ} \mathrm{C}$ and glued to small hooks of silver wire. The next day they were attached to the torque meter in the flight simulator (Fig. 1) and their pattern preference with respect to an upright and an inverted T-shaped figure was recorded for consecutive 2-min periods (Fig. 2). HU flies, like the controls, flew readily once tarsal contact was removed. The percentage that kept flying during the whole 18-min recording period was similar in the HU and control flies (HU flies: 83.3\%; controls: 91.4\%; P > 0.05 , contingency $\chi^{2}$ ).
To adjust the zero setting of the angular velocity with respect to the fly's yaw torque range at the onset of the experiment, the flight simulator mode was interrupted and the arena was briefly rotated exafferently in both directions. MB-less flies showed normal-sized optomotor responses to these motion stimuli (no data were recorded). During the first $2 \mathrm{~min}$ in the flight simulator mode no heat was applied. Flies had the opportunity to gather experience with the highly artificial feedback conditions (Guo et al. 1996). The HU flies kept optomotor balance without any difficulty and generated typical torque spikes at a normal rate (Heisenberg and Wolf 1979, 1993). Like the controls, they had the tendency to fixate on the patterns and showed a slight preference for the inverted $T$ (not show $n$ ).

After 2 min the training began. Flies were conditioned with heat as reinforcer to avoid certain flight directions with respect to the two patterns in the panorama. The flies quickly learned to keep their course out of the heat. Already during the first 2 -min period of training flies reached an avoidance score of $\mathrm{P}=0.5$ implying that they were heated for $<25 \%$ of the time. HU flies avoided the heat as effectively as the controls (Fig. 2) suggesting that neither the MBs nor the missing parts of the antennal lobes are essential for heat reception or active heat avoidance (see Discussion).

After the 4-min training period, heat was switched off and the fly's pattern preference was tested for $2 \mathrm{~min}$. In the MB-less flies, as well as in the controls, the conditioning procedure had shifted the pattern preference toward the "no heat" pattern. This result indicates that neither pattern recognition nor learning and memory of visual a

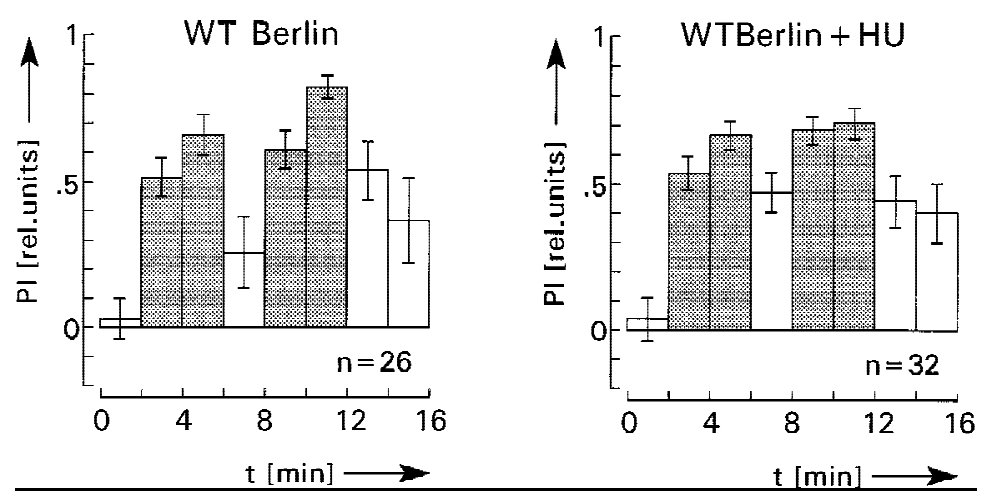

Figure 2: O perant conditioning in the flight simulator. Heat is used as reinforcer and flight direction with respect to landmarks as heatcontrolling behavior. Experimental time is subdivided into 2-min periods. The sequence consists of a preference test (left bar in $a$ and b), two 4-min training periods (shaded bars) and two memory tests (open bars between and after training). Performance indices (PIs) are calculated as $\mathrm{PI}=\left(t_{a}-t_{b}\right) /\left(t_{a}+t_{b}\right)$, with $t_{a}$ indicates the time the fly spends in a "cold" sector and $t_{b}$ the time the fly is oriented toward a "hot" sector. Error bars are S.E.M. for the number ( $n$ ) of flies. No significant differences of Pls during memory tests can be observed between normal (a) and $\mathrm{HU}$-treated flies without mushroom bodies (b). Comparing the first memory tests (betw een the training blocks) in $a$ and $b$, the two-sided $P$ value (alternate $t$-test) is $>0.1$. For the last two memory tests it is $P>0.5$.

$\begin{array}{llllllllllllllll}L & E & A & R & N & I & N & G & \underset{169}{\mathbf{X}} & M & E & M & O & R & Y\end{array}$ 
Wolf et al.

pattern preferences depend on the MBs. This is in contrast to the requirement of the MBs in odor recognition or odor preference learning as discussed in the Introduction. After the first memory test the training was repeated for another 4 min and finally the fly was subjected to a second memory test. No significant difference was observed between MB-less and normal flies (Fig. 2).

A similar conclusion was reached using the mutant $\mathrm{mbm}^{1}$. The present $\mathrm{mbm}^{1}$ stock was backcrossed to WT Berlin, as described by de Belle and Heisenberg (1996), and contains $>90 \%$ females with severely reduced MBs. These flies, how ever, have a low motivation to fly. Many of them stop during the recording period and have to be reactivated by sudden air puffs. Only $60 \%$ of the $\mathrm{mbm}^{1}$ flies glued to the hook (see Materials and Methods) flew long enough to finish the entire 18-min experiment (control flies, $85 \%$ ). Although this difference was not statistically significant (see Materials and Methods for statistical tests), the observation is supported by many similar studies. Nevertheless, for the flies that finished the experiment, flight performance, heat avoidance, pattern recognition, and spontaneous pattern preferences w ere normal. Although the memory test scores appeared lower than those of the wild type, the differences were not statistically significant (Fig. 3).

\section{VISUAL OSCILLATIONS AS NEGATIVE REINFORCEMENT}

In the following experiment we changed the reinforcer. Instead of heating the flies we superimposed a $5-\mathrm{Hz}$ oscillation $\left( \pm 7.5^{\circ} \mathrm{A}_{\mathrm{pp}}\right)$ upon the reafferent movement of the panorama at the nonpermissive pattern orientations. Normal flies readily avoided this "turbulence" during the training and later, in the memory test, showed a marked preference for those patterns that promised a calm flight (Fig. 4a). HU flies had no obvious impairment in any phase of this experiment. They perceived the fast oscillation, avoided it, and developed a preference for flight orientations for which oscillation was not to be expected. Evidently, this purely visual learning task does not require the MBs (Fig. $4 b)$.

\section{CLASSIC CONDITIONING AT THE TORQUE METER}

In olfactory classic conditioning (Tully and Quinn 1985) intact MBs are required (de Belle and Heisenberg 1994; Connolly et al. 1996). We considered the possibility that classic conditioning might present a greater challenge than operant conditioning and that intact MBs might be required only in classic forms of learning.

In the flight simulator the training phase can easily be changed into a classic procedure. The feedback loop between the fly's yaw torque and the angular velocity of the arena was opened and the arena movement was controlled by a fixed schedule. The arena alternated betw een tw 0 orientations at 3-sec intervals, one with the upright $T$ and the other with the inverted $T$ in front of the fly (Fig. 5a). Flies were heated with one of the pattern orientations as before, but now they received heat for $50 \%$ of the time. Therefore, the heat had to be reduced slightly to make it tolerable for the fly. During training no PI was calculated (see Fig. 5bd). In the memory test the apparatus was sw itched back to the flight simulator mode as this is the only way the fly's pattern preference can be assessed. The overall time schedule was the same as in the experiments of Figure 3, that is, 4 min of pretest in the flight simulator without heat, 4 min of training (stationary patterns), a 2-min memory test (flight a

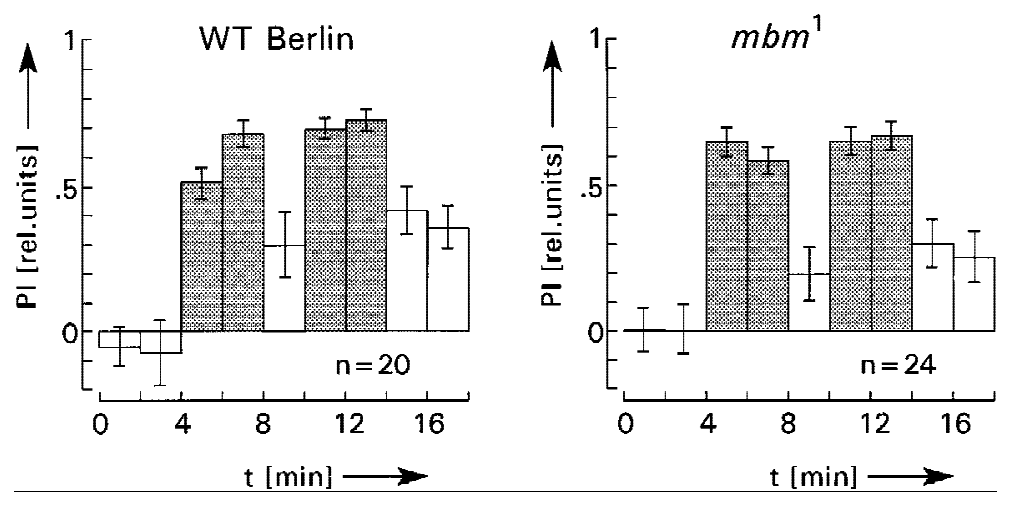

b
Figure 3: Comparison of operant visual learning of wild type (a) and $\mathrm{mbm}^{1}$ flies (b). As with the HU flies and control flies in Fig. 2 no significant differences of PIs during memory tests can be observed between wild type and $\mathrm{mbm}^{1}$. The two-sided $P$ value (alternate $t$-test) is $>0.1$ for all three corresponding memory tests in $a$ and $b$. Experimental details as in Fig. 2, with the exception of two 2-min preference tests before the first training. 
a

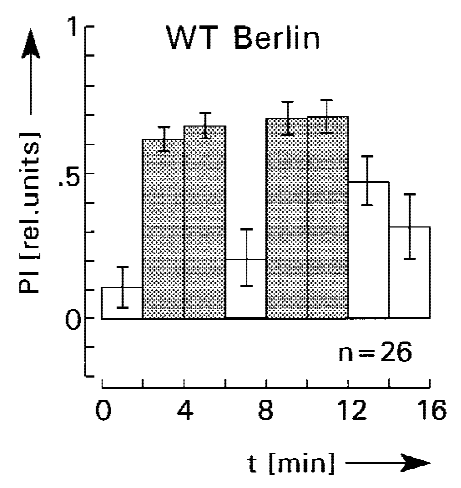

b

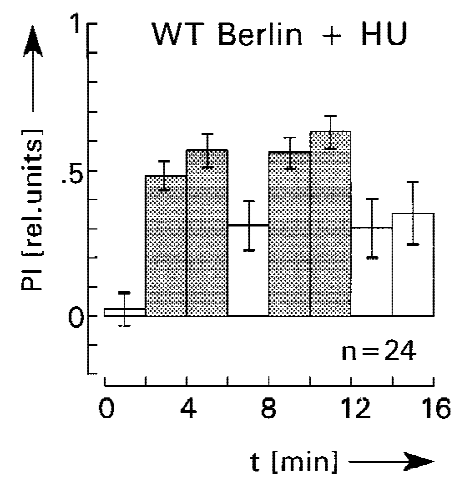

Figure 4: $\quad$ O perant visual learning with superimposed visual oscillations (turbulences) as reinforcer (instead of heat). O scillation amplitude $A_{p p}=15^{\circ} \mathrm{C}$, frequency $\mathrm{f}=5 \mathrm{~Hz}$. Avoidance and memory scores are about the same for normal (a) and $\mathrm{HU}$-treated flies without mushroom bodies (b) $P>0.1$ for comparison of all three corresponding memory tests in a and $b$. Experimental details as in Fig. 2. simulator mode), again 4 min of training (stationary patterns), and a final 4-min memory test (flight simulator mode). The result for normal flies is shown in Figure $5 \mathrm{~b}$. After classic conditioning, memory scores are about as high as in the operant experiment.
The operant nature of the conditioning in the original experiment of Figure 2 had been revealed by the so-called replay experiment (Wolf and Heisenberg 1991), which is reminiscent of a yoked control. Flies were passively exposed to a sequence of pattern movements and heat/no heat a

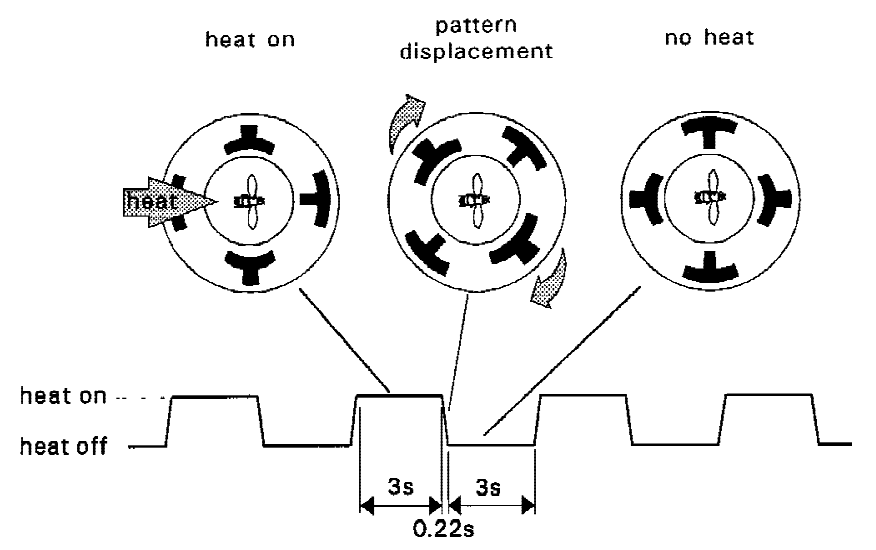

b

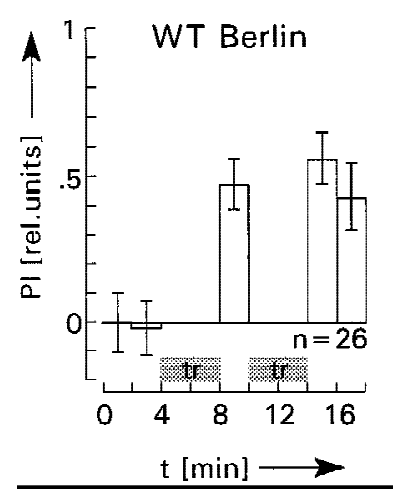

$c$

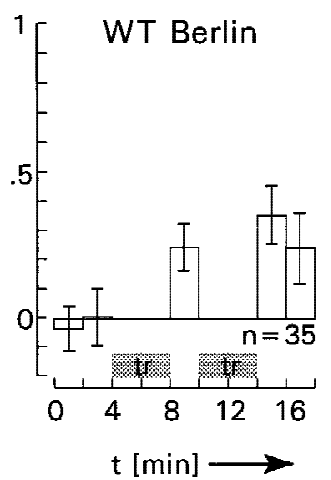

d

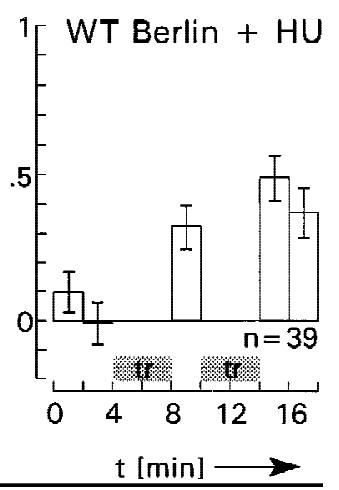

Figure 5: Classic conditioning in the flight simulator with normal $(b, c)$ and HU-treated, MB-less flies (d). During training (a), the flight simulator mode is switched off. Two stable pattern orientations are presented to the fly (upright or inverted $\mathbf{T}$ in frontal position) and are interchanged every $3 \mathrm{sec}$ (displacement period, $220 \mathrm{msec}$ ). With one of the pattern orientations heat is on (top) and with the other it is off (top). This procedure is repeated continuously during the entire training period of $4 \mathrm{~min}$. The two 2-min preference tests as well as the learning tests are performed operantly in the flight simulator mode. During tests, $\mathrm{PI}$ is evaluated as $\mathrm{PI}=\left(t_{a}-{ }_{b}\right) /\left(t_{a}+t_{b}\right)$ (see Fig. 2), except that here $t_{a}$ and $t_{b}$ indicate the time during which flight is directed toward a narrow sector of $\pm 3^{\circ} \mathrm{C}$ around the center positions of the patterns. During training, $t_{a}=t_{b}$, therefore, $\mathrm{PI}$ is zero (gaps between preference tests and first memory test, and between first and second memory test in $b-d$ ). In $c$ the arena illumination is switched off during the 220 msec of pattern displacement to present only retina-stabilized images during training (see text for further explanations). Eliminating the pattern movement and introducing the "dark flashes" has no significant effect on preference and memory scores (for PIs of first memory tests, $P>0.05$; of the final memory tests, $P>0.1$ ). (d) As al ready established in the operant conditioning experiments (Figs. 2-4), $\mathrm{HU}$-treated MB-less flies learn and remember as well as the controls in $b$. Error bars are S.E.M. for the number ( $n$ ) of flies. 
Wolf et al.

alternations that had been recorded from flies trained in the flight simulator mode. With this kind of classic conditioning no positive memory scores were obtained. The result could be interpreted to indicate that the motivational state of flies without visual feedback was incompatible with learning or memory (e.g., stress as a result of the lack of feedback). The new finding rules out this kind of explanation. Flies are able to acquire classically conditioned pattern preferences and display them subsequently in the flight simulator mode if sufficient reinforcement is applied. The fly's active role in controlling pattern orientation and temperature seems to facilitate the association between conditioned and unconditioned stimulus (B. Brembs and M. Heisenberg, in prep.).

In the operant conditioning procedure the fly has the opportunity to modify its motor programs by trial and error until it finds a strategy that improves its situation (conditioned response). For instance, the fly might find out that it is advantageous to immediately reverse its turning direction when the temperature gets too high. Obviously, during classic conditioning the fly has no opportunity to acquire any such strategies. Thus, the new result demonstrates that positive memory scores do not necessarily depend on learned motor programs. The acquired pattern preference in Drosophila, therefore, can be interpreted as a central state that is largely independent of motor output.

The classic conditioning experiment addresses a further point of interest. In human subjects stabilized retinal images quickly fade aw ay (e.g., Riggs et al. 1953). In the classic training of the experiment in Figure $5 b$ the flies are exposed to stabilized retinal images. The positive memory scores show that they recognize and remember them. It is a remote possibility that the flies learn the patterns while they are changing their angular position. To rule out this possibility, we have darkened the arena during the 220-msec displacement period ("dark flashes"). With this regimen we obtain memory scores in the normal range (Fig. $5 c$; in Fig. $5 b, d$ memory scores are unusually high; differences with and without dark flashes are not significant). Thus, in the present case the memory template cannot be a "motion signature," as has been discussed for Drosophila (Dill et al. 1995) and other insects (e.g., Zeil 1993). Srinivasan et al. (1993) have shown that honeybees can learn the orientation of contours without motion cues. In our case, even flickering the image seems not to be essential for visibility (although switching on the light once after the dark flash might be considered a minimal flicker stimulus).

The main question posed in this section was whether the MBs are required in visual learning and memory if the flies are prevented from learning by trial and error. In the experiment shown in Figure $5 \mathrm{~d}$ HU flies were subjected to the classic conditioning procedure. They learned and remembered as well as the controls. As mentioned in $\mathrm{Ma}$ terials and Methods, the flies were sacrificed for histology after the experiment and were individually inspected to verify the MB ablation. Obviously, MBs are not involved in this associative process. [R. Wolf and M. Heisenberg (unpubl.) have reported an experiment showing that in HU flies dark flashes interfere with short-term memory in this paradigm. Work is in progress investigating whether this behavioral deficit can be assigned definitively to the MBs.]

\section{MOTOR LEARNING AT THE TORQUE METER}

In the next experiment MB-less flies were tested in a motor learning task not involving vision. This paradigm has been described by Wolf and Heisenberg (1991). The fly was flying at the torque meter in an illuminated arena without any visual motion feedback or explicit stationary patterns. The whole range of spontaneously generated yaw torque was arbitrarily divided by the computer into two halves corresponding roughly to the domains for left and right turns in free flight. During training heat was applied whenever yaw torque was in one of the domains. The fly readily adjusted its yaw torque range to avoid being heated and kept this reduced range even after heat was permanently switched off. Figure 6 shows avoidance and memory scores for $\mathrm{HU}$ flies and control flies. As pointed out earlier (Wolf and Heisenberg 1991), the first difficulty for the fly in this experiment is to detect that it is the yaw torque that matters with respect to temperature. The second step is the lasting modification of the yaw torque range. Apparently, the MBs are not involved in either of these processes.

\section{SPATIAL LEARNING OF FREELY WALKING FLIES IN THE HEATING CHAMBER}

Recently, Wustmann et al. (1996) have developed a simple device to test spatial learning in

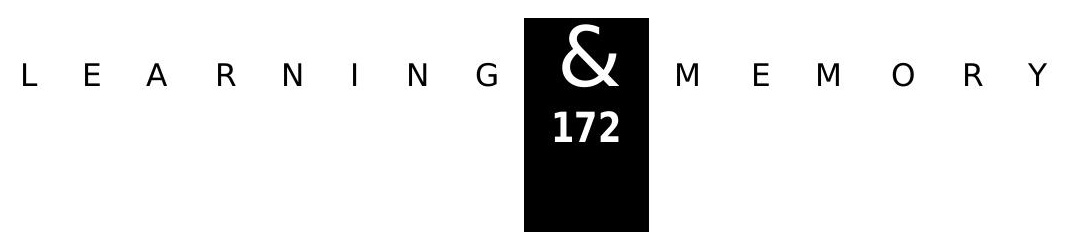




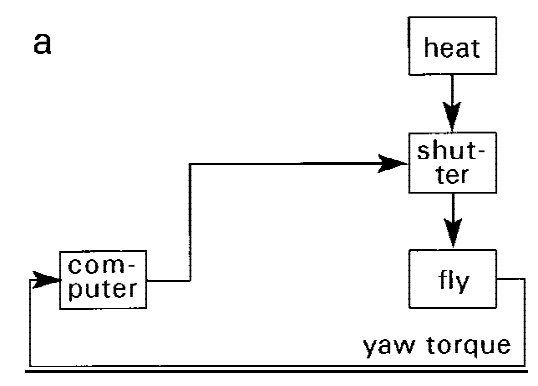

b

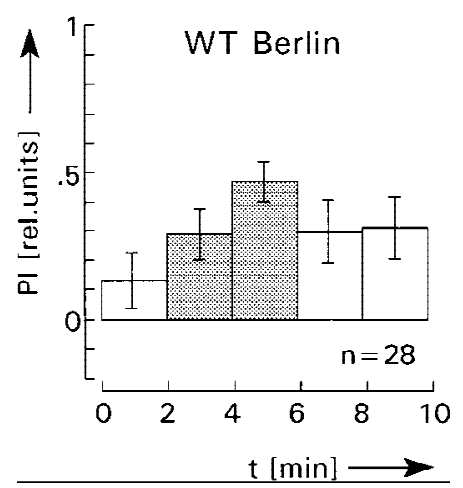

C

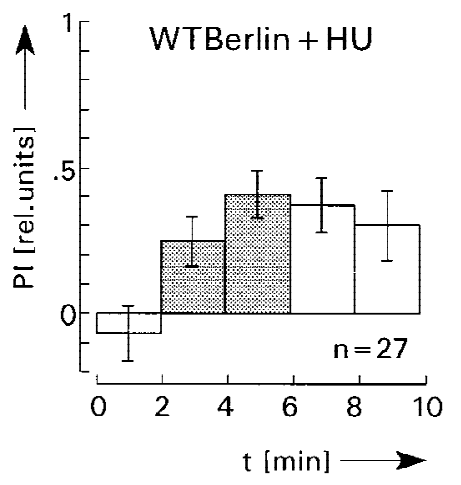

Figure 6: Motor learning at the torque meter. (a) Block diagram of experimental procedure (see text for further explanations). In contrast to the experiments of Figs. 2-5 no visual patterns or motion stimuli are involved. The range of spontaneously generated yaw torque values is recorded and divided by the computer into two domains corresponding roughly to right and left turns in free flight. During training (shaded bars), heat is switched on in one domain and turned off in the other. Flies learn to control the heat by directing yaw torque preferentially to one of the domains. After 4 min of training, flies continue to avoid yaw torque values that had previously been associated with heat (last two bars in $b$ and $c)$. There is no significant difference in memory performance between HU flies $(c)$ and control $(b)$ flies $(P>0.5$ for comparison of the corresponding memory PIs). PIs are evaluated as PI $=\left(t_{a}-t_{b}\right) /\left(t_{a}+t_{b}\right)$ where $t_{a}$ indicates the time during which the shutter is closed and $t_{b}$ the time during which it is opened. Error bars are S.E.M. for the number $(n)$ of flies.

freely walking single flies. It consists of a small chamber that can be heated instantaneously by Peltier elements above and below the fly. A directional light gate in the middle of the chamber monitors whether the fly is in one or the other half. The experiment consists of a preference test, a training test, and a memory test. During training the entire chamber is heated to $37^{\circ} \mathrm{C}$ whenever the fly is on one side of the light gate and cooled to $25^{\circ} \mathrm{C}$ if the fly is on the other side. Most flies rapidly learn to avoid the hot side and keep their acquired side preference even during the subsequent memory test without heat (for details of the procedure, see Materials and Methods).

The entire experiment can be conducted in complete darkness. Wustmann and Heisenberg (1997) have show $n$ that in this case the fly has only tactile and ideothetic (self-generated) cues for its spatial orientation in the chamber. If in a different experiment visual landmarks [yellow and blue lightemitting diodes (LEDs)] are provided, normal flies rely on both visual and tactile/ideothetic cues. In both versions of the test MB-less flies were not measurably impaired (Fig. 7), indicating that the MBs are not essential for telling the fly where in the chamber it is in relation to the invisible potential heat threat. The LEDs as visual landmarks for orientation did not confuse the flies. Because HU flies have a largely normal visual system (see above) we assume that like the control flies they use the visual cues for orientation if these are provided. It cannot be excluded, how ever, that they just ignore them.

\section{Discussion}

A total of 18 associative learning tasks have now been tested in MB-less flies (Table 1 ). Together they provide an unambiguous answ er to the question whether the MBs are a general device for associative learning and memory. The answer is no. Fortunately, presence or absence of MBs is easily and unambiguously show $\mathrm{n}$ for the individual fly and if MB-less flies obtained with one kind of technique can be show $n$ to perform normally in a learning paradigm, no further controls and no other methods of blocking the MB pathway need to be explored. Only if a behavioral deficit is observed, as in the case of odor discrimination conditioning, it is important to use several different routes of intervention to make sure that it is indeed the block in the MBs causing the abnormality.

It may not be a big surprise that motor learning at the torque meter works properly in MB-less flies. After all, posture learning and the plasticity of simple sensory motor responses can be observed in decapitated insects including Drosophila (Horridge 1962; Hoyle 1980; Booker and Quinn 1981; 
Wolf et al.

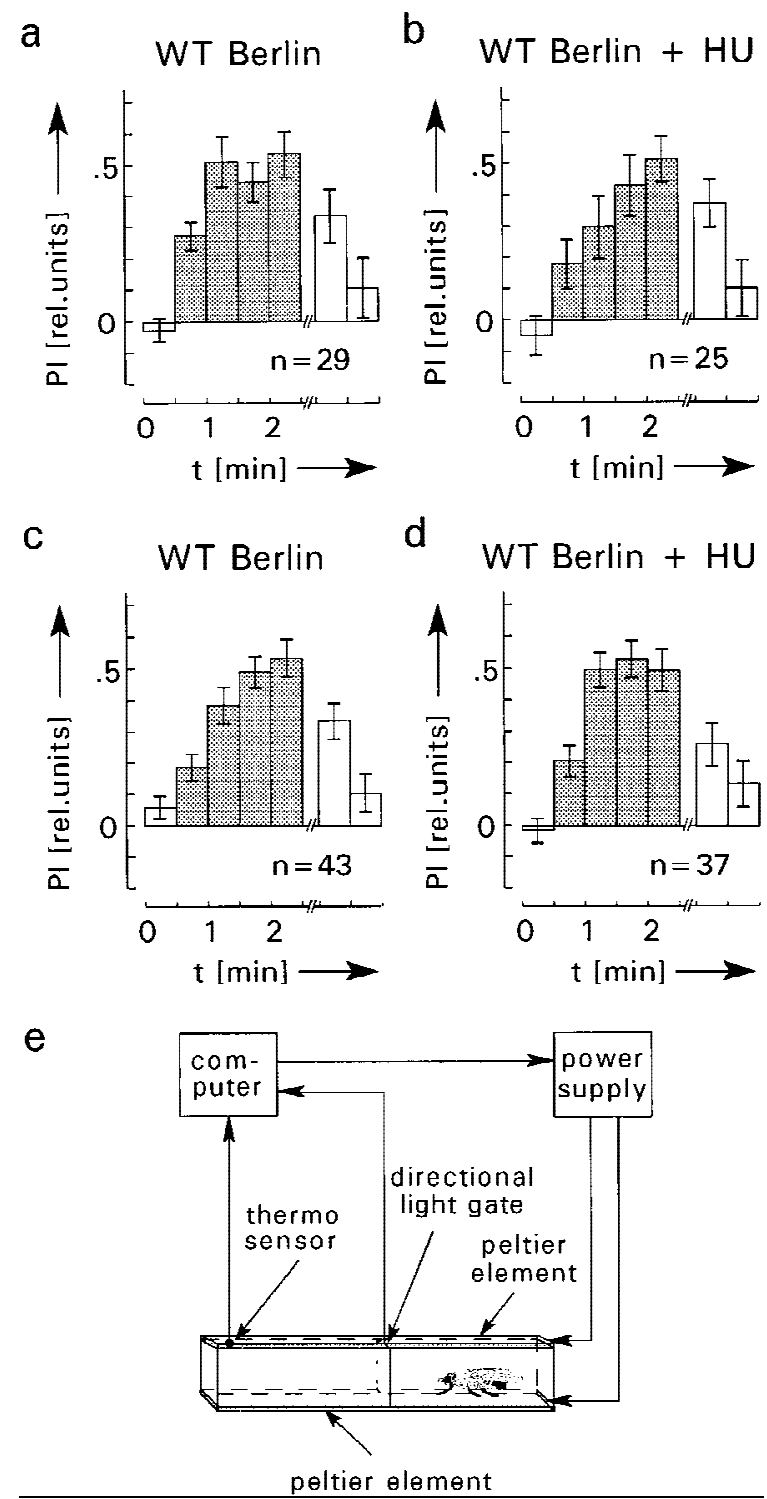

Figure 7: Spatial learning and memory in the heating chamber. (a- $d$ ) Average PI before (first, open bar), during (crosshatched bars), and after avoidance training (last two, open bars). $\mathrm{PI}$ is defined as $\mathrm{PI}=\left(t_{a}-t_{b}\right) /$ $\left(t_{a}+t_{b}\right)$, where $t_{a}$ is the time the fly spends on the side associated with no heat and $t_{b}$ the time on the heatassociated side. In $a$ and $b$ the chamber and the laboratory are illuminated during the entire experiment, whereas in $c$ and $d$ all lights are switched off, that is, flies are in complete darkness. The infrared light gate is not visible. No significant differences of the Pls in light and darkness are observed. Also, avoidance and memory scores of $\mathrm{HU}$-treated and control flies are not significantly different $(P>0.1$ for comparison of the corresponding PIs after training). Error bars are S.E.M. for the number $(n)$ of flies. (e) Heating chamber for operant conditioning, after Wustmann et al. (1996). For further explanations, see text.
Corfas and Dudai 1989). Taking this older study into account there could not have been any doubt that some instances of associative learning work without MBs. However, because in Drosophila thermoreception is mediated by the antennae (Sayeed and Benzer 1996), an involvement of the MB pathway did not seem totally unlikely. It would be most interesting to determine where in the central nervous system the efference copy of the yaw torque motor program is correlated with the temporal modulation of thermoreception (Wolf and Heisenberg 1991). Our present results indicate that the MBs are not involved in this process.

More surprisingly, the MBs are dispensable in all visual learning tasks investigated so far. These involve freely walking and stationarily flying animals, as w ell as both classic and operant associative learning. Several suggestions regarding the function of the MBs can now be rejected. For instance, the hypothesis that MBs might serve as matrices for memory templates (Heisenberg 1989, 1994) must be discarded regarding visual pattern recognition. Stationary and moving visual patterns as well as different light intensities and colors (cited in Heisenberg et al. 1985; Heisenberg 1994) can be learned by MB-less flies as conditioned stimuli. Another suggestion had been that the MBs might be required to adjust and accommodate the different time courses of the conditioned and unconditioned stimuli (summarized in Erber et al. 1987). Again, independent of the stimulus used as negative or positive reinforcer (heat, vigorous shaking, visual oscillations, sucrose), MB-less flies have no difficulty to learn the task. Even the remarkable ability of Drosophila to cope with the inversion of visual feedback in the flight simulator (Heisenberg and Wolf 1984) is not impaired in MB-less flies (Heisenberg 1989). In all these cases, no tests for long-term memory have been performed. It cannot be excluded, therefore, that these memory traces are less stable than in the controls.

In three of the experiments we tested visual learning in the flight simulator. The finding that MB-less flies learn and remember properly under these conditions also implies that they can perform basic visual flight control. Drescher (1960) has reported an increased latency of the optomotor response in cockroaches with lesioned calyces. Such an effect, if present in MB-less Drosophila, would probably have dramatic consequences in the flight simulator and would hardly remain undiscovered. Nevertheless, the tests conducted so far account only for a few selected aspects of the fly's visual 
Table 1: Paradigms of associative conditioning that have been tested with MB-less flies

\begin{tabular}{|c|c|c|c|c|c|c|c|}
\hline learning paradign & CS & US & $\begin{array}{l}\text { behavior in } \\
\text { nienory test }\end{array}$ & $\begin{array}{l}\text { type of } \\
\text { training }\end{array}$ & $\begin{array}{c}\text { type of } \\
\text { intervention }\end{array}$ & deficit & $\begin{array}{c}\text { references } \\
\text { a) paradigm; b) intervention }\end{array}$ \\
\hline odor preference & odors & $\begin{array}{l}\text { electric } \\
\text { shock }\end{array}$ & $\begin{array}{l}\text { free walk } \\
\text { choice in } T \text { - } \\
\text { maze }\end{array}$ & classical & $\begin{array}{l}m b m^{\prime} \\
\text { HU-ablation } \\
\text { Gas }\end{array}$ & yes & $\begin{array}{l}\text { a) Tully and Quinn, } 1985 \\
\text { b) deBelle and Heisenberg, } 1996 \\
\text { deBelle and Heisenberg, } 1994 \\
\text { Connolly et al. } 1996\end{array}$ \\
\hline odor avoidance & odors & $\begin{array}{l}\text { clectric } \\
\text { shock }\end{array}$ & $\begin{array}{l}\text { free walk } \\
\text { fast phototaxis }\end{array}$ & mixed & $m b m, m b d$ & yes & $\begin{array}{l}\text { a) Quinn et al., } 1974 \\
\text { b) Heisenberg et al., } 1985\end{array}$ \\
\hline odor avoidance & odors & sucrose & $\begin{array}{l}\text { free walk } \\
\text { fast phototaxis }\end{array}$ & mixed & $m b m^{1}, m b d$ & yes & $\begin{array}{l}\text { a) Tempel et al., } 1983 \\
\text { b) Heisenberg et al., } 1985\end{array}$ \\
\hline arena test & odors & sucrose & $\begin{array}{l}\text { free walk } \\
\text { food search }\end{array}$ & operant & $m b m, m b d$ & yes & a / b) Heisenberg et al., 1985 \\
\hline $\begin{array}{l}\text { larval odor } \\
\text { preference }\end{array}$ & odors & $\begin{array}{l}\text { electric } \\
\text { shock }\end{array}$ & $\begin{array}{l}\text { crawling } \\
\text { odor choice }\end{array}$ & classical & $m b m^{\prime}$ & yes & $\begin{array}{l}\text { a) Aceves-Pina and Quinn, } 1979 \\
\text { b) Heisenberg et al. } 1985\end{array}$ \\
\hline $\begin{array}{l}\text { proboscis } \\
\text { extention reflex }\end{array}$ & sucrose & quinine & $\begin{array}{l}\text { tethered walk } \\
\text { proboscis ext. }\end{array}$ & operant & $m b m^{1}$ & yes & $\begin{array}{l}\text { a) DeJianne et al ., } 1984 \\
\text { b) Médioni, cited in Heisenberg, } \\
1989\end{array}$ \\
\hline $\begin{array}{l}\text { courtship } \\
\text { suppression } \\
\text { by mated female }\end{array}$ & & $\begin{array}{l}\text { anti- } \\
\text { aphro- } \\
\text { disiacs }\end{array}$ & $\begin{array}{l}\text { free walk } \\
\text { male courtship }\end{array}$ & operant & $m b d$ & no & $\begin{array}{l}\text { a) Siegel and Hall, } 1979 \\
\text { b) Heisenberg. } 1994\end{array}$ \\
\hline $\begin{array}{l}\text { inversion of visuo- } \\
\text { motor coupling }\end{array}$ & & & $\begin{array}{l}\text { flight } \\
\text { simulator }\end{array}$ & operant & $m b m, m b d$ & no & $\begin{array}{l}\text { a) Heisenberg and Wolf, } 1984 \\
\text { b) cited in Heisenberg, } 1989\end{array}$ \\
\hline color choice & colors & $\begin{array}{l}\text { mech. } \\
\text { shaking }\end{array}$ & free walk & classical & $m b d$ & no & $\begin{array}{l}\text { a) Menne and Spat, } 1977 \\
\text { b) cited in Heisenberg et al., } 1985\end{array}$ \\
\hline intensity contrast & $\begin{array}{l}\text { light } \\
\text { intens. }\end{array}$ & $\begin{array}{l}\text { mech. } \\
\text { shaking }\end{array}$ & free walk & classical & $m b d$ & no & ibid \\
\hline arena test & colors & sucrose & $\begin{array}{l}\text { frec walk } \\
\text { food search }\end{array}$ & $\begin{array}{l}\text { operant or } \\
\text { classical }\end{array}$ & $m b d$ & no & a/b) Heisenberg, 1989 \\
\hline heat avoidance & $\begin{array}{l}\text { visual } \\
\text { patterns }\end{array}$ & heat & $\begin{array}{l}\text { flight } \\
\text { simulator }\end{array}$ & operant & $\begin{array}{l}\text { HU ablation } \\
m b m^{\prime}\end{array}$ & no & $\begin{array}{l}\text { a) Wolf and Heisenberg, } 1991 \\
\text { b) this work }\end{array}$ \\
\hline heat avoid ance & $\begin{array}{l}\text { stationary } \\
\text { vis.patt. }\end{array}$ & heat & $\begin{array}{l}\text { flight } \\
\text { simulator }\end{array}$ & classical & HU ablation & no & $\mathrm{a} / \mathrm{b}$ ) this work \\
\hline heat avoidance & $\begin{array}{l}\text { color or } \\
\text { intensity } \\
\text { contrast }\end{array}$ & heat & $\begin{array}{l}\text { flight } \\
\text { simulator }\end{array}$ & operant & $\mathrm{mbm}$ & no & $\begin{array}{l}\text { a) Wolf and Heisenberg, } 1997 \\
\text { b) Wolf and Heisenberg, unpub- } \\
\text { lished preliminary data }\end{array}$ \\
\hline $\begin{array}{l}\text { avoidance of } \\
\text { "turbulences" }\end{array}$ & $\begin{array}{l}\text { visual } \\
\text { patterns }\end{array}$ & $\begin{array}{l}\text { visual } \\
\text { ose. }\end{array}$ & $\begin{array}{l}\text { flight } \\
\text { simulator }\end{array}$ & operant & HU ablation & no & $\mathrm{a} / \mathrm{b})$ this work \\
\hline motor learning & & heat & yaw torque & operant & HU ablation & no & $\begin{array}{l}\text { a) Wolf and Heisenberg, } 1991 \\
\text { b) this work }\end{array}$ \\
\hline $\begin{array}{l}\text { spatial learning in } \\
\text { heating chamber }\end{array}$ & $\begin{array}{l}\text { visual, } \\
\text { tactile. }\end{array}$ & heat & free walk & operant & HU ablation & no & $\begin{array}{l}\text { a) Wustmann et al., } 1996 \\
\text { b) this work }\end{array}$ \\
\hline $\begin{array}{l}\text { spatial learning in } \\
\text { heating chamber }\end{array}$ & tactile & heat & free walk & operant & HU ablation & no & ibid \\
\hline
\end{tabular}

(HU) Hydroxyurea; $\left(\mathrm{G}_{\mathrm{s}}\right)$ transgenic expression of a constitutively activated G-protein $\alpha_{\mathrm{s}}$ subunit in the Kenyon cells; for further explanations see text.

abilities. The recent finding that visual experience influences the size of the calyx (Barth and Heisenberg 1997) should encourage a detailed search for visual functions that require the MBs.

Recently, Mizunami et al. (1993) generated mechanical lesions in the MBs of Periplaneta americana. The operated animals performed poorly in a spatial memory task. Our result with MB-less flies performing the spatial learning test in the heating chamber is not in accord with their observation. Several factors may account for the discrepancy. The two paradigms have very different designs (size of arena, difficulty of search, sen- sory cues, etc.). Moreover, Drosophila has a lobetype MB, and Periplaneta has a calyx-type MB. Also, it should be kept in mind that with one kind of intervention alone it is difficult to assign a behavioral function to a particular neural structure, as one cannot be certain that the intervention has no effects outside of the target structure.

So far, the only behavioral function shown to require intact MBs is olfactory learning. As discussed in the Introduction, converging evidence from honeybees, ants, and Drosophila indicates beyond a reasonable doubt that learning or remembering odors is impaired whenever the MB path- 
Wolf et al.

way is blocked. No other behavioral paradigm has been sufficiently tested with several independent methods of intervention to warrant a similar conclusion (but see Martin et al. 1998). Considering that so far all conditioning experiments involving chemical signals as conditioned stimuli have been sensitive to MB ablation, it is interesting that conditioned courtship suppression by mated females works properly without MBs [preliminary data on the mutant mbd cited in Heisenberg 1994; and recent experiments of E. Savvateeva (in prep.) using the HU ablation technique]. This finding underscores the importance of nonchemical cues [the physical presence of the courted fly or dummy (Tompkins et al. 1983)], which the courting male associates with the anti-aphrodisiac pheromones of the mated female.

For Drosophila, MB mutants, the HU ablation technique, and a growing collection of specific $M B$ enhancer strains allowing to direct suitable effector genes to the Kenyon cells, now make a systematic search for MB functions in behavior feasible. Several candidate behaviors all involving chemoreception have been tentatively assigned to the MBs. Among them are gustatory learning (J. Médioni, cited in Heisenberg 1989), mate recognition (Ferveur et al. 1995; O'Dell et al. 1995), and spontaneous odor preferences (Heisenberg 1989). It remains a great challenge to determine in more detail how the MB pathway, or more specifically the properties of the Kenyon cells influence behavior. Behavioral analysis will be indispensible to understand how the MB pathway contributes to the functioning of the brain.

\section{Acknowledgments}

We thank S. Flurschütz for technical assistance and S. Kramer for valuable comments on the manuscript. This work was supported by Deutsche Forschungsgemeinschaft (He986) and Alexander-von-Humbold-Foundation (L.L.).

The publication costs of this article were defrayed in part by payment of page charges. This article must therefore be hereby marked "advertisement" in accordance with 18 USC section 1734 solely to indicate this fact.

\section{References}

Aceves-Piña, E.O. and W.G. Quinn. 1979. Learning in normal and mutant Drosophila larvae. Science 26: 93-96.

Barth, M. and M. Heisenberg. 1997. Vision affects mushroom bodies and central complex in Drosophila melanogaster. Learn. \& Mem. 4: 219-229.

Booker, R. and W.G. Quinn. 1981. Conditioning of leg position in normal and mutant Drosophila. Proc. Natl. Acad. Sci. 78: 3940-3944.

Connolly, J.B., I.J.H. Roberts, J.D. Armstrong, K. Kaiser, M. Forte, T. Tully, and C.J. O 'Kane. 1996. Associative learning disrupted by impaired $\mathrm{G}_{\mathrm{S}}$ signaling in Drosophila mushroom bodies. Science 274: 2104-2107.

Corfas, G. and Y. Dudai. 1989. Habituation and dishabituation of a cleaning reflex in normal and mutant Drosophila. J. Neurosci. 9: 56-62.

de Belle, J.S. and M. Heisenberg. 1994. Associative odor learning in Drosophila abolished by chemical ablation of mushroom bodies. Science 263: 692-695.

- - . 1996. Expression of Drosophila mushroom body mutations in alternative genetic backgrounds: A case study of the mushroom body miniature gene $(\mathrm{mbm})$. Proc. Natl. Acad. Sci. 93: 9875-9880.

Dejianne, D., T.R. McGuire, and A. Pruzan-Hotchkiss. 1984. Pavlovian counterconditioning of proboscis extension in Drosophila melanogaster. J. Comp. Psychol. 99: 74-80.

Dill, M., R. Wolf, and M. Heisenberg. 1995. Behavioral analysis of Drosophila landmark learning in the flight simulator. Learn. \& Mem. 2: 152-160.

Drescher, W. 1960. Regenerationsversuche am Gehirn von Periplaneta americana unter Berücksichtigung von Verhaltensänderung und Neurosekretion. Z. Morphol. Ö kol. Tiere 48: 576-649.

Dujardin, F. 1850. Memoires sur le systeme nerveux des insectes. Ann. Sci. Nat. (Zool.) 14: 195-205.

Erber, J., T. Masuhr, and R. Menzel. 1980. Localization of short-term memory in the brain of the bee Apis mellifera. Physiol. Entomol. 5: 343-358.

Erber, J., U. Homberg, and W. Gronenberg. 1987. Functional roles of the mushroom bodies in insects. In Arthropod brain. Its evolution, development, structure, and functions (ed. A.P. Gupta), pp. 485-511. John Wiley, New York, NY.

Ferveur, J.F., K.F. Stoertkuhl, R.F. Stocker, and R.J. Greenspan. 1995. Genetic feminization of brain structures and changed sexual orientation in male Drosophila melanogaster. Science 267: 902-905.

Guo, A., L. Liu, S.-Z. Xia, C.-H. Feng, R. Wolf, and M. Heisenberg. 1996. Conditioned visual flight orientation in Drosophila: Dependence on age, practice and diet. Learn. \& Mem. 3: 49-59.

Hanström, B. 1928. Vergleichende Anatomie des Nervensystems der wirbellosen Tiere. Springer Verlag, Berlin, Germany.

Heisenberg, M. 1989. Genetic approach to learning and memory (mnemogenetics) in Drosophila melanogaster.

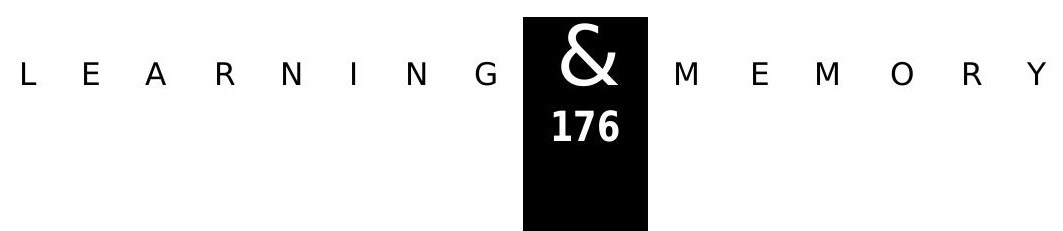




\section{LEARNING IN MUSHROOM BODY-LESS FLIES}

Neuronal plasticity and brain function. Fortschr. Zool. 37: 3-45.

1994. Central brain function in insects: Genetic studies on the mushroom bodies and central complex in Drosophila. Neural Basis of behavioural adaptations. Fortschr. Zool. 39: 61-79.

Heisenberg, M. and R. Wolf. 1979. On the fine structure of yaw torque in visual flight orientation of Drosophila melanogaster. J. Comp. Physiol. 130: 113-130.

- - . 1984. Vision in D rosophila. In Studies of bran function, Vol. XII (ed. V. Braitenberg). Springer-Verlag, Berlin, Germany.

- - . 1988. Reafferent control of optomotor yaw torque in Drosophila melanogaster. J. Comp. Physiol. A 163: 373-388.

- - . 1993. The sensory-motor link in motion-dependent flight control of flies. In Visual motion and its role in the stabilization of gaze (ed. F.A. Miles and J. W allmann), pp. 265-283. Elsevier Science, N ew York, NY.

Heisenberg, M., A. Borst, S. Wagner, and D. Byers. 1985. Drosophila mushroom body mutants are deficient in olfactory learning. J. Neurogenet. 2: 1-30.

Horridge, G.A. 1962. Learning of leg positions by headless insects. Nature 193: 697-698.

Howse, P.E. 1974. Design and function in the insect brain. In Experimental analysis of insect behaviour (ed. L.

Barton-Brown), pp. 180-194. Springer, Berlin, Germany.

Hoyle, G. 1980. Learning using natural reinforments in insect preparations that permit cellular neuronal analysis. J. Neurobiol. 11: 323-354.

Huber, F. 1960. Untersuchungen über die Funktion des Zentralnervensystems und insbesondere des Gehirns bei der Fortbewegung und der Lauterzeugung der Grillen. Z. Vergl. Physiol. 44: 60-132.

Ito, K. and Y. Hotta. 1991. Proliferation pattern of postembryonic neuroblasts in the brain of Drosophila melanogaster. Dev. Biol. 149: 134-148.

Kloot van der, W.G. and C.M. Williams. 1954. Cocoon construction by the Cecropia silkworm. III. The alteration of spinning behavior by chemical and surgical techniques. Behaviour 6: 233-255.

Martin, J.R., R. Ernst, and M. Heisenberg. 1998. Mushroom bodies suppress locomotor activity in D rosophila melanogaster. Learn. \& Mem. (this issue).

Masuhr, T. 1976. "Lokalisation und Funktion des Kurzzeitgedächtnisses der Honigbiene (Apis mellifera L.)." Ph.D. Dissertation. Fachbereich Biologie, TH Darmstadt, Germany.
Menne, D. and H.C. Spatz. 1977. Color vision in Drosophila melanogaster. J. Comp. Physiol. A 114: 301-312.

Mizunami, M., J.M. Weibrecht, and N.J. Strausfeld. 1993. A new role for the insect mushroom bodies: Place memory and motor control. In Biological neural networks in invertebrate neuroethology and robotics (ed. R.D. Beer, R.E. Ritzman, and T. McKenna), pp. 199-225. Academic Press, N ew York, NY.

O 'Dell, K.M.C., J.D. Armstrong, M.Y. Yang, and K. Kaiser. 1995. Functional dissection of the Drosophila mushroom bodies by selective feminization of genetically defined subcompartments. Neuron 15: 55-61.

Prokop, A. and G.M. Technau. 1994. Normal function of the mushroom body defect gene of Drosophila is required for the regulation of the number and proliferation of neuroblasts.

Dev. Biol. 161: 321-337.

Q uinn, W.G., W.A. Harris, and S. Benzer. 1974. Conditioned behavior in Drosophila melanogaster. Proc. Natl. Acad. Sci. 71: 708-712.

Riggs, L.A., F. Ratliff, J.C. Cornsweet, and T.N. Cornsweet. 1953. The disappearance of steadily fixated visual test objects. J. Opt. Soc. Am. 43: 495-501.

Sachs, L. 1992. Angewandte statistik, 7th ed. Springer, Berlin, Germany.

Sayeed, O. and S. Benzer. 1996. Behavioral genetics of thermosensation and hygrosensation in Drosophila. Proc. Natl. Acad. Sci. 93: 6079-6084.

Schürmann, F.W. 1987. The architecture of the mushroom bodies and related neuropils in the insect brain. In Arthropod brain: Its evolution, development, structure, and functions (ed. A.G. Gupta), pp. 231-264. John Wiley \& Sons, N ew York, NY.

Siegel, R.W. and J.C. Hall. 1979. Conditioned responses in courtship behavior of normal and mutant Drosophila. Proc. Natl. Acad. Sci. 76: 3430-3434.

Srinivasan, M.V., S.W. Zhang, and B. Rolfe. 1993. Is pattern vision in insects mediated by "cortical" processing? Nature 362: 539-540.

Tempel, B.L., N. Bonini, D.R. Dawson, and W.G. Quinn. 1983. Reward learning in normal and mutant Drosophila. Proc. Natl. Acad. Sci. 80: 1482-1486.

Tompkins, L., J.C. Hall, and L.M. Hall. 1983. Conditioned courtship in Drosphila and its mediation by association of chemical cues. Behav. Genet. 13: 565-578.

Tully, T. and W.G. Quinn. 1985. Classical conditioning and retention in normal and mutant Drosophila melanogaster. J. Comp. Physiol. A 157: 263-277.

Voskresenskaja, A.K. 1957. On the role played by mushroom bodies (corpora pedunculata) on the supraesophageal 
Wolf et al.

ganglion in the conditioned reflexes of the honey bee. Dokl. Akad. Nauk. SSSR 112: 964-967.

Vowles, D.M. 1964. Olfactory learning and brain lesions in the wood ant (Formica rufa). J. Comp. Physiol. Psychol.

58: 105-111.

Wolf, R. and M. Heisenberg. 1991. Basic organization of operant behavior as revealed in Drosophila flight orientation. J. Comp. Physiol. A 169: 699-705.

1997. Visual space from visual motion: Turn integration in tethered flying Drosophila. Learn. \& M em. 4: 318-327.

W ustmann, G. and M. Heisenberg. 1997. Behavioral manipulation of retrieval in a spatial memory task for Drosophila melanogaster. Learn. \& Mem. 4: 328-336.

W ustmann, G., K. Rein, R. Wolf, and M. Heisenberg. 1996. A new paradigm for operant conditioning of Drosophila melanogaster. J. Comp. Physiol. A 179: 429-436.

Zeil, J. 1993. O rientation flights of solitary wasps (Cerceris; Sphecidae; Hymenoptera) II. Similarities between orientation and return flights and the use of motion parallax. J. Comp. Physiol. A 172: 207-222.

Received January 26, 1998; accepted in revised form April 17, 1998. 


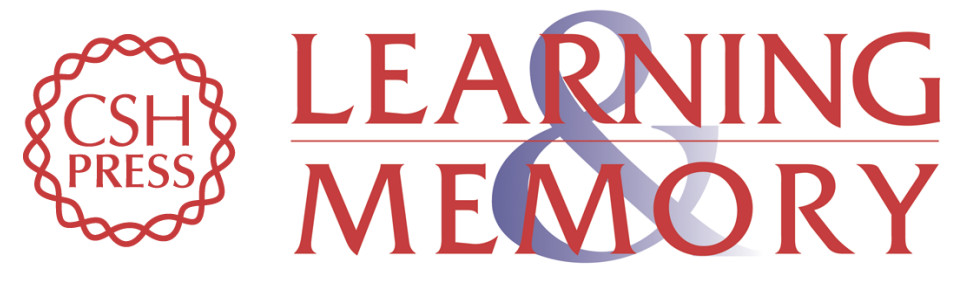

\section{Drosophila Mushroom Bodies Are Dispensable for Visual, Tactile, and Motor Learning}

Reinhard Wolf, Tobias Wittig, Li Liu, et al.

Learn. Mem. 1998, 5:

Access the most recent version at doi:10.1101//m.5.1.166

References This article cites 39 articles, 15 of which can be accessed free at:

http://learnmem.cshlp.org/content/5/1/166.full.html\#ref-list-1

License

Email Alerting Receive free email alerts when new articles cite this article - sign up in the box at the Service top right corner of the article or click here. 